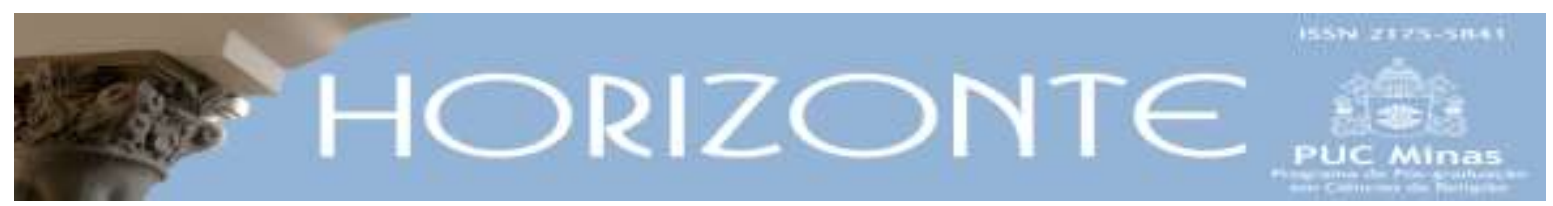

Temática Livre - Artigo Original

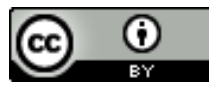

DOI - 10.5752/P.2175-5841.2016v14n44p1421

\title{
O Espírito Santo e o cuidado na Igreja
}

\author{
The Holy Spirit and the care in the Church
}

José Neivaldo de Souza*

\begin{abstract}
Resumo
O objetivo deste ensaio é refletir sobre a relação Espírito Santo e o cuidado na Igreja. A Bíblia apresenta esta trajetória na organização e libertação de um povo: em primeiro lugar através da lei e os profetas; depois, por meio do Messias e, por último, pela missão da Igreja. Espírito e cuidado se encontram nas metáforas da eleição, do Messias, da maternidade e da inspiração. Estas metáforas unem os dois testamentos e trata da reciprocidade entre Deus e seu povo. A obra de Deus é revelada e comunicada, através do cuidado, pelo Espírito Santo. A Igreja, seguindo as orientações bíblicas, e à luz do mesmo Espírito, busca discernir os sinais da salvação. No Primeiro Testamento podem-se perceber seus sinais na formulação e cumprimento das leis, na expressão dos Cânticos e dos Salmos e também nas pregações dos profetas. No Segundo Testamento ele é testemunhado nos evangelhos e, de forma particular, na pessoa de Jesus Cristo, através de sua vida. A obra de Deus é revelada e comunicada, através do cuidado, pelo Espírito Santo. A Igreja, seguindo as orientações bíblicas, e à luz do mesmo Espírito, busca discernir os sinais da salvação. Nesta orientação o objetivo desta reflexão é apresentar a trajetória do Espírito Santo que se manifesta enquanto cuidado.
\end{abstract}

Palavras-chave: Espírito. Metáfora. Testamentos. Igreja. Cuidado.

\begin{abstract}
The purpose of this essay is to reflect on the link Holy Spirit and care in the Church. The Bible presents this trajectory in the organization and liberation of a people: firstly, through the rules and the prophets; secondly through the Messiah and, finally, the Church's mission. Spirit and care converge in the metaphors of election, of the Messiah, maternity and inspiration. These metaphors unite the two Testaments and deal with the reciprocity between God and his people. The work of God is revealed and communicated through the care of the Holy Spirit. The Church, following the Biblical guidelines, and in the light of the Spirit, seeks to discern the signs of salvation. In the First Testament we can perceive its signs in the formulation and enforcement of laws, in the words of Solomon and the Psalms and also in the preaching of the prophets. In the Second Testament, it is witnessed in the Gospels and, particularly, in the person of Jesus Christ, through his life. The work of God is revealed and communicated through the care of the Holy Spirit. The Church, following the Biblical guidelines, and in the light of the Spirit, seek to discern the signs of salvation. In this way, the purpose of this reflection is to present the trajectory of the Holy Spirit manifested in care.
\end{abstract}

Keywords: Spirit. Metaphor. Testaments. Church. Care.

\footnotetext{
Artigo submetido em 31 de julho de 2016 e aprovado em 25 de novembro de 2016.

* Doutor em Teologia pela Pontificia Universitas Gregoriana de Roma (1996), mestre em Teologia pela Pontifícia Faculdade de Teologia Teresianum (1994), mestre em Psicologia Clínica pela Universidade Tuiuti do Paraná (2003) e mestre em Filosofia pela Pontificia Studiorum Angelicum (1995). País de Origem: Brasil. E-mail: neivaldo.js@gmail.com
}

Horizonte, Belo Horizonte, v. 14, n. 44, p. 1421-1435, out./dez. 2016 - ISSN 2175-5841 


\section{Introdução}

A dimensão espiritual é, ao mesmo tempo, de natureza invisível e visível. De um lado, pode ser abordada pela via puramente racional e, por outro, é na história que ela revela o seu rosto. Em outras palavras, é nesta dialética que o Espirito deseja se manifestar. É através de um rosto, como bem diz o filósofo Emmanuel Lévinas, que ele quer se comunicar. O rosto é sinal de alteridade. Nele se inscreve todo fundamento ético. O Espírito Santo se revela progressivamente através dos tempos. No Primeiro Testamento podem-se perceber seus sinais na formulação e cumprimento das leis, na expressão dos Cânticos e dos Salmos e também nas pregações dos profetas (Is 61,1-2). No Segundo Testamento ele é testemunhado nos evangelhos e, de forma particular, na pessoa de Jesus Cristo, através de sua vida (Lc 4,16-22; Mt 11, 25-27; Mc 12,28-31). Para os cristãos, ele se manifesta na prática do cuidado apresentada não só pelos testemunhos bíblicos, mas pela Igreja que, em seu ministério pastoral, pretende ser sinal do Reino de Deus na terra.

Françoise Mies apresenta uma leitura interessante acerca de Emmanuel Lévinas observando que, apesar do filósofo não trabalhar exclusivamente com metáforas, se pode perceber em suas obras que ele lança mão de metáforas no trato da relação Espírito e cuidado: eleição, Messias, maternidade e inspiração são termos que expressam essencialmente a alteridade do Espirito. Há outras metáforas, que não serão tratadas aqui, que apresentam o Espírito Santo como fogo, vento, etc. Sua atuação está sempre ligada à responsabilidade de Deus em relação ao povo ou à natureza. Atua de forma especifica na criação e depois na salvação de um povo.

Há no ser humano algo que o torna mais que um complexo de corpo e alma. Pelo Espírito o ser é impulsionado a decidir por uma realidade, um rosto. Mas que rosto? Os dois Testamentos o apresentam e a Igreja, seguindo estas apresentações, procura seguir. É o rosto do estrangeiro, da viúva e do órfão; dos oprimidos, dos famintos e daqueles que sofrem pela falta de sentido. O rosto ou o "tu" que convida a compreender as diferenças (HABERMAS, 2013, p. 13). 
Nesta orientação o objetivo desta reflexão é apresentar "uma" trajetória do Espírito Santo que se manifesta enquanto cuidado. No Primeiro Testamento, no Segundo Testamento e na ação da Igreja. Sabe-se que o tema é amplo e exigiria uma vasta pesquisa sobre o assunto, por isso serão escolhidos alguns textos bíblicos e autores que ajudem a pensar a manifestação do Espírito na prática do cuidado e da responsabilidade.

\section{Primeiro Testamento: manifestações do Espírito}

O Primeiro Testamento ajuda a discernir a presença do Espirito na natureza e na história humana. Podem-se abordar alguns sinais deste Espírito na narrativa da criação, nos profetas, nos salmos e na lei. Alguns textos mostram isso. A primeira menção ao Espirito está em Gênesis 1,2 onde o poeta, ao narrar sobre a criação, observa que antes de tudo acontecer: "O Espírito de Deus movia-se sobre as águas”. Este mesmo Espírito, a Ruah, age na história de um povo que caminha em busca de sentido. Ele age através de líderes carismáticos como os Patriarcas, Moisés e Josué; Juízes destemidos como Gedeão, Jefte, Sansão e Samuel; reis tementes a Deus como Davi (1Sm 16,13), Salomão, Josias e outros; através de profetas da justiça (Zc 7,12) como Isaías (61-1-2), e Ezequiel $(11,5)$, etc. Tanto profetas quanto salmistas caracterizam o Espírito como "Santo" (Is 63, 10,11; Sl 51,13), isto é, dom absolutamente transcendente e gratuito que atua sobre as criaturas e que deve ser invocado e acolhido. Por sua ação dinâmica (Is 30,28) a pessoa abandona o egoísmo e, na liberdade, vivencia a integridade da criação, a verdade e o amor.

Pode-se dizer que na Antiga Aliança o Espírito está presente na narrativa da criação, na profecia e na lei. No ato criador $(\mathrm{Gn} 1,2)$ o Espírito aparece como ruah. A terra não tinha forma e o que se via era só trevas. O Espírito de Deus se move sobre a face das águas dando forma e trazendo à luz a vida. Aqui se pode pensar o Espírito em sua dimensão feminina. No ventre divino se forma a criação e, por sua 
energia, é posta à luz. Para Yves Congar o Espírito é uma energia de vida, ela age e faz agir; anima e faz animar (CONGAR, 2005, p. 18). Esta ideia aparece no livro do Êxodo quando o Senhor incumbe Moisés de ser o libertador e legislador de seu povo; escolhe Bezalel e o enche de seu Espírito dando-lhe destreza e habilidade para desenhar e formar trabalhos em ouro, prata, bronze, pedras, madeira, e qualquer tipo de material (Ex 31,2-5).

A lei é a expressão desta energia de vida e indica responsabilidade no trato com a criação, com Deus e com o semelhante. Ela procura, com justiça, orientar o povo de Israel. Três passagens, apesar de existirem mais, mostram a ligação do Espírito com a formação e cumprimento da Lei de Deus. Israel, acampado tribo por tribo, recebe o Espírito de Deus (Nm 24,2). O Espírito que está sobre Moisés será compartilhado com uma liderança a fim de organizar e conduzir o povo segundo a lei de Deus (Nm 11,17). Mais tarde, Josué, substitui Moisés e, cheio do Espírito de sabedoria, conduz os israelitas à obediência e à lei de Deus (Nm 34,9).

Esta energia de vida aparece também no movimento profético em que Samuel é precursor. Samuel toma sobre si a responsabilidade de ungir Davi: toma um chifre cheio de óleo e o derrama sobre aquele que iria fortalecer a monarquia em Israel: “o Espírito do Senhor apoderou-se de Davi” (1Sm 16, 13). Praticamente todos os profetas fazem alusão ao Espírito de Deus ou à energia de vida. Em particular, Isaias, Ezequiel e Miqueias fazem menção a esta força responsável e "transformadora". O eleito é ungido e inspirado. A Ruah que vem do alto derramando vida aos lugares inférteis (Is 32,15) é a mesma que repousa sobre o eleito dando a ele sabedoria, entendimento, conselho, poder, conhecimento, temor do Senhor (Is 11,2), justiça (Is 42,1) e cuidado (Is 61,1). Em Ezequiel o mesmo Espírito que "forma” a criação e "conforma” a palavra dos profetas é capaz de “reformar” uma nação “deformada” pelo pecado: Israel (Ez 39,29; Mq 3,8).

O Espírito, na concepção veterotestamentária, é quem dá a vida a toda criatura, elege aqueles com quem ele conta para difundir o seu sopro (sua Palavra), 
unge-os para santificar a criação e os inspira para a justiça e a integridade. Para Mies, Emmanuel Lévinas inspira à teologia ao tratar as Escrituras como metáforas do "si" ou da responsabilidade do eu no confronto com o outro. ${ }^{1}$ Entre as metáforas há aquelas que apontam para uma experiência espiritual fundante no Primeiro Testamento e que serão retomadas no Segundo Testamento. Uma leitura de Lévinas, por François Mies, chama atenção. Ele ressalta conceitos como: Maternidade, Eleição, Messias e inspiração (MIES, 2012, p. 113-156).

A maternidade trata da responsabilidade. Assim como Deus gera a criação em seu interior, o "eu”, em suas entranhas, gera e acolhe o outro ainda que não o tenha escolhido. Este outro, relacionado ao povo de Deus é o estrangeiro, o forasteiro, o sofredor. Estes aparecem ao eu sob um rosto que demanda: “A metáfora da maternidade explica essa estrutura do si, afetado pelo outro até em sua carne, uma estrutura do si responsável pelo outro, com uma responsabilidade não escolhida com prévia liberdade: o outro me compete, sem o ter escolhido" (MIES, 2012, p. 125). O Espírito Santo, em sua dimensão feminina, é quem por primeiro acolhe e dá vida. Ele instiga, através de sinais, à responsabilidade e ao cuidado com o outro, principalmente aquele que não tem vez e nem voz. Não foram poucas as mulheres do Primeiro Testamento a assumirem a maternidade como vontade divina. As parteiras do Egito, por exemplo, desobedeceram ao faraó e por conta disso, cuidaram para que os hebreus sobrevivessem e fossem libertos por Moisés, “salvo das águas”.

Da mesma forma o conceito de eleição, não diz de um favoritismo divino, mas de um chamado do Espírito à responsabilidade. Não há na bíblia hebraica o termo "eleição". Ele é traduzido do verbo hebraico Bãhar que denota: escolher. Aparece inicialmente no livro de Gênesis ( $\mathrm{Gn} 6,2 ; 13,11)$, porém na maioria das vezes como ação de Deus. No face a face o outro se dirige ao eu, único e irredutível, elegendo-o a uma missão que exige cuidado. Este eu não é e nunca será o outro,

\footnotetext{
${ }^{1}$ Metáfora aqui é entendida como figura de linguagem que indica "transposição" ou substituição de termo por outro revelando uma relação de semelhança.
} 
pois a "ipseidade" lhe é essencial, isto é, o "si" é para o outro sem perder sua identidade, como escreve Mies: "é aquilo que faz de mim eu mesmo e não outra pessoa, ou mais exatamente, o que me faz "si" é a responsabilidade em relação ao outro (MIES, 2012, p. 121).

O eleito é também ungido, tornando-se o Messias, ele pode ser compreendido na responsabilidade do "eu" em relação ao outro. Esta ideia aponta para o servo sofredor destinado a carregar sobre "si mesmo" o sofrimento alheio. Ainda que levado à tortura e à morte, ele assume toda responsabilidade de seus atos sem imputar a outrem culpa alguma: "não posso abandonar a ninguém a missão de Messias, sob pena de imoralidade e convite ao martírio” (MIES, 2012, p. 124).

A inspiração aponta também para a responsabilidade face ao outro que inspira. Para Mies, Lévinas trata desta metáfora, assim como as outras, entendendo que o "eu”, sem se dar conta, se vê autor de algo que lhe veio de fora e, sem saber de onde é contra sua vontade e não lhe pertence: "Essa inspiração do si pelo outro, do si respondendo ao mandamento “não matarás”, é ética” (MIES, 2012, p. 126).

Esta Ipseidade, o que faz com que um ser seja ele mesmo e não outro engendra a alteridade. ${ }^{2}$ De fato não só o Deuteronômio atesta isso, mas o evangelho de Marcos (Mc 12,28-31) revela esta ideia ao narrar a resposta de Jesus ao escriba acerca dos mandamentos: Amar a Deus e ao próximo como a si mesmo.

Mies faz entender que as metáforas de Lévinas, apesar de abordadas sob o ponto de vista ético-filosófica, têm lugar numa teologia pneumatológica, pois traz clareza sobre a responsabilidade que cada fiel assume por meio do Espírito de acolhida, de eleição, de unção e inspiração. É pelo Espírito que profetas e escritores sagrados comunicaram a Vontade divina e, por inspiração deste mesmo Espírito, o Texto é lido, compreendido e vivido.

${ }^{2}$ Ipseidade: o ser idêntico a si mesmo. Alteridade: o que determina a diferença de um ser do outro ser. 
Deus é Espirito (Jo 4,24), “o outro por excelência, o outro enquanto outro, aquele que é completamente outro". Lévinas entende que o próximo também é o outro, apesar de ser "infinitamente menos outro do que aquele que é absolutamente o outro" (LÉVINAS, 2003, p. 36). É pelo Espírito que "as faltas em relação ao próximo são, ipso facto, ofensas a Deus”(LÉVINAS, 2003, p. 37). Para Lévinas a relação com o outrem é pré-ontológica, do campo da religião, já que o vinculo com outrem não se reduz à representação de outrem, mas à sua invocação. A invocação precede à compreensão (LÉVINAS, 2005, p. 29). Nesta perspectiva, ele entende que o inicio do pensamento está na possibilidade de perceber uma liberdade exterior à minha: “o mundo da percepção manifesta um rosto" (LÉVINAS, 2005, p. 39).

No Segundo Testamento o Espírito é "Revelatus” num rosto. Em Jesus de Nazaré confluem todas as metáforas utilizadas no passado para falar do Espírito escondido. Nele se cumprirá perfeitamente todas as promessas da Ruah divina.

\section{O Segundo Testamento: revelação do Espírito}

Esta energia de vida, a Ruah, na Bíblia hebraica, é a ação de Deus. Através dela Ele se revela a fim de vivificar e animar. Pelo Espírito, Deus conduz o seu povo suscitando heróis, guerreiros, reis, líderes (CONGAR, 2005, p. 30). Pode-se perceber, como Yves Congar, que na Antiga Aliança o Espírito divino "era ativo e, portanto, estava presente naqueles que realizavam sua obra: reis, profetas, fiéis piedosos o serviam fielmente. Incontestavelmente, porém, o Espírito não é concedido nem revelado na Antiga Aliança nas mesmas condições que na Nova, a da Encarnação e de Pentecostes" (CONGAR, 2005, p. 103).

O Evento da encarnação dá seus sinais na apresentação de Jesus no Templo, como requeria a Lei antiga. Havia um homem justo e piedoso chamado Simeão, o Espirito Santo estava sobre ele e lhe revelou que não morreria antes de ver o Cristo, a consolação de Israel. Simeão tomou o menino nos braços e bendisse a Deus pelo 
cumprimento da promessa dizendo que ele já podia partir em paz, pois os seus olhos viram a salvação para os gentios e para o povo de Israel (Lc 2,25-32).

$\mathrm{Na}$ perspectiva deuterotestamentária pode-se entender as principais metáforas, ressaltadas no Primeiro Testamento. Jesus, logo no inicio de seu ministério, revela a eternidade do Espírito que se manifesta nos gestos de acolhida, de eleição, de unção e inspiração. Na sinagoga de Nazaré o mestre lê a passagem da Escritura ressaltando a missão de Isaias (Is 61,1-2), missão esta com implicações éticas claras: responsabilidade e cuidado em relação ao outro, o rosto desfigurado e oprimido que clama por compaixão: "O Espirito do Senhor está sobre mim, porque ele me ungiu para pregar boas novas aos pobres. Ele me enviou para proclamar liberdade aos presos e recuperação da vista aos cegos, para libertar os oprimidos" (Lc 4, 18). O tema do Espírito Santo e o cuidado perpassa o Segundo Testamento e começa logo no inicio do ministério de Jesus.

Em Marcos Jesus aparece como a promessa de salvação, na medida em que ao ser batizado por João Batista, no rio Jordão, é reconhecido como aquele que batiza com Espírito Santo. Por ocasião de seu batismo, Jesus é declarado o Messias de Deus, sob a descida do Espírito Santo: "Então veio dos céus uma voz: "Tu és o meu Filho amado; de ti me agrado"' (Mc 1,11). Sob o Espírito Santo Jesus conduz sua vida, fala de sua missão (Lc 4), vence as tentações e escolhe os doze (Mc 1,1720) para que, com ele, possa implantar o Reino de Deus e dar testemunho da obra de salvação (At 10,38-39).

A literatura dá testemunho do sentido e a Bíblia não se caracteriza como prova, no trato científico do termo, mas traduz uma tradição ou vivência no Espirito de onde surge toda experiência de Deus. Numa perspectiva teológica, como se propõe esta reflexão, pode-se dizer que não há teologia sem experiência espiritual (CODINA, 2010, p. 19). Fazer teologia sem abordar a tradição bíblica e seu entendimento acerca do Espírito é negligenciar a importância dos testemunhos acerca deste mesmo Espírito. Paul Tillich, nos passos de Lévinas, entende que não 
se pode abordar o Espírito se não for a partir do encontro. Para ele, o eu busca se centrar no encontro com o outro eu centrado (TILLICH, 2005, p.502). E, nesta experiência o Espírito revela à Igreja, o lugar da responsabilidade, da ternura e do cuidado com o outro.

Em Pentecostes, da mesma forma, o Espírito se revela. No mesmo dia em que, segundo a lei dos judeus, se devia apresentar uma oferta de cereal novo ao Senhor (Lv 23,16), os discípulos presenciaram na casa onde se reuniram algo parecido com línguas de fogo a descer sobre cada um deles: "todos ficaram cheios do Espírito Santo e começaram a falar noutras línguas, conforme o Espírito os capacitava” (At 2,4). Codina resume a ação do Espírito, no Novo Testamento: sua atuação sobre Maria, sua descida sobre Jesus, guiando sua vida profética e fazendo nascer a Igreja; o mesmo Espírito que ressuscita Jesus inspira e mobiliza a evangelização em Atos, em Paulo e nos escritos joaninos (CODINA, 2010, p.44).

\section{A Igreja: espiritualidade e cuidado}

Mas, de que Espírito trata a tradição da Igreja? O Espírito, por sua dimensão impessoal e misteriosa, inspira a Escritura e nela se manifesta em forma de metáforas, uma forma de dizer o indizível. Entre as metáforas, indicadas por Lévinas, como responsabilidade e cuidado em relação ao outro, outras podem ser ressaltadas, principalmente as que tratam da ação da natureza e que servirão à igreja como símbolo do Espírito em suas liturgias: fogo, água, óleo, perfume, vinho, pão etc. Para Victor Codina a maioria desses símbolos não tem rosto, mas se orienta a um rosto e implica responsabilidade no processo de salvação: "para conhecer e discernir um Espírito é preciso constatar se conduz a Jesus ou levam a Jesus" (CODINA, 2010, p.32).

A Igreja nasce da fé na encarnação e da certeza do seu querígma em Pentecostes. Ela sofreu perseguições, mas se edificou encorajada pelo Espirito Santo e no temor do Senhor (At 9,31). Em seu conselho o apóstolo Paulo diz aos 
bispos para cuidar do rebanho sobre o qual o Espírito Santo os havia colocado como líderes (At 20, 28). Em apocalipse João escreve que toda orientação das igrejas deve vir do Espírito Santo (Ap 2,7). A Bíblia apresenta o Espírito Santo em metáforas e, a maioria delas expressa uma energia que anima e orienta à vida. Pode-se dizer, com isso, que Deus compartilha, pelo Espírito Santo, a responsabilidade e o cuidado com a vida.

O Espírito Santo está intimamente ligado ao dogma da Santíssima Trindade. O Espirito Santo não pode ser entendido fora da relação: Pai e Filho. Um só Deus em três pessoas. Para alguns Pais da Igreja não se pode contemplar o Espírito Santo separadamente ou fora do mistério trinitário. Eis uma teologia essencialmente pneumatológica construída pelos primeiros pensadores da Igreja, cuja obra compõe o alicerce do edifício eclesial. A economia da salvação deve ser pensada a partir das três pessoas divinas.

Antes do Concilio de Niceia a pneumatologia patrística se desenvolveu a partir da fórmula batismal de Mateus (Mt 28,18-19). O Espírito Santo, ao lado do Pai e do Filho, foi pensado como o inspirador das Escrituras, preexistente de Cristo. Ele elege aqueles a quem destina os dons e liga a fé dos fiéis ao Espírito divino. A teologia desta época, sob a influência helênica, se debruça sobre a relação Pai e Filho-Logos (BOLGIANI, 2002, p. 507). Sobre isso escreveu Clemente Romano: "que o Deus que tudo vê e é Senhor dos espíritos e de todos os seres vivos - que elegeu o Senhor Jesus Cristo e, por meio dele, nos elegeu para sermos o seu povo particular - conceda a toda pessoa que invoca o seu nome magnifico e santo, a fé, o temor, a paz, a perseverança, a paciência, a continência, a pureza e a moderação" (CLEMENTE, 1985, p. 70). Esta teologia, pouco definida sobre o Espírito Santo, seguirá até o concilio de Niceia (325).

A partir de Niceia aparecem reflexões mais sistemáticas por autores como: Atanásio de Alexandria, Basílio de Cesareia, Gregório Nazianzo e Gregório de Nissa. Para eles, o Espírito Santo deve ser não só compreendido na Trindade, mas 
adorado no mesmo nível do Pai e do Filho, pois invés de "coisa” é uma Pessoa que, apesar de distinta, possui a mesma essência. Ele, acolhido pelo Filho, provém do Pai. Esta reflexão prenunciou o Concilio de Constantinopla (381) cuja importância se tem pelo lugar que dá ao Espírito Santo na Confissão de Fé: “Creio no Espírito Santo, Senhor e fonte de vida, que procede do Pai; e com o Pai e o Filho é adorado e glorificado: Ele que falou pelos profetas”.

Basílio de Cesareia, em seu Tratado Sobre o Espírito Santo, caracterizava bem a terceira pessoa da Santíssima Trindade: "Por meio dele, elevam-se os corações, os fracos são conduzidos pela mão, os que progridem chegam à perfeição. Ele é que, iluminando os que se purificaram de toda mácula, transforma-os em espirituais, através da comunhão com ele” (BASILIO DE CEZARÉIA, 1998, p. 120). Para o teólogo de Cesareia a Igreja não pode adorar o Filho Unigênito (Jo 1,18), e tampouco invocar o Pai, a não ser no Espírito Santo.

Santo Agostinho foi o grande teólogo pós-Constantinopla, foi responsável por sustentar o dogma da Trindade e defender o Espírito Santo como aquele que difunde no coração da Igreja a caridade trinitária. (AGOSTINHO, 1998, p. 49). A Igreja, segundo esta perspectiva, deve ser formada à imagem da Trindade, sob a inspiração do Espírito Santo.

A missão da Igreja, como portadora da boa noticia da salvação, é difundir esta certeza da fé: a salvação é a obra do Pai realizada no Filho pelo Espírito. O Espírito Santo aponta para o Filho como o realizador, por excelência, da graça salvífica do Pai. Pelo mesmo Espírito, como bem escreve São Paulo (Rm 5,5), Deus continua cuidando da criação e derramando o seu amor "em nossos corações".

A Igreja é chamada, à luz do Espírito Santo, Senhor e fonte de vida, a cuidar da vida. Manifestando-se na solicitude do cuidado, o Espírito anuncia sua dedicação e desprendimento de si. Nesta perspectiva, a Igreja renuncia o legalismo e o imperialismo do ego no trato com o diferente e denuncia toda forma de 
opressão e preconceito. Pode-se dizer que o Espírito decide pela vida em abundância, manifestando-se como solicitude no trato da salvação.

Como solicitude, no cuidado espiritual, o Espírito dá os seus frutos, como escreveu Paulo na epistola aos Gálatas: "Fruto do Espírito é: amor, alegria, paz, paciência, benignidade, bondade, fidelidade, mansidão e domínio próprio" (Gl 5, 22-23a). São valores que transcendem uma existência segundo a própria natureza. Assim, quem vive segundo o Espírito, tem a mente e o corpo voltados para o Espirito. Em síntese, pode-se dizer que o Espírito é ser para o outro (MARTINS, 2010, p. 20). Na solicitude do cuidado com a saúde física, o Espírito dá os seus frutos também na enfermidade. Nesta perspectiva, doença não é oposição à saúde, mas dela faz parte. Quem preza pelo cuidado e decide pelo outro é capaz de enfrentar a intempéries da vida, principalmente aquelas que se manifestam nas enfermidades. O enfermo, sob esta visão, não pode ser condenado e tampouco ser julgado por sua situação. O evangelho de João (Jo 9,1-3) relata a reação dos discípulos de Jesus diante de um cego de nascença. Eles perguntam ao mestre sobre a causa daquela doença e o Rabi ensina-lhes que nem ele e nem os pais dele pecaram, mas tudo isso aconteceu para que a Glória de Deus se manifestasse. Através de Jesus, Deus não faz acepção de pessoas e quem dá essa compreensão é o Espirito Santo.

Na solicitude com a saúde psíquica, cuidar da alma é, acima de tudo, olhar pra si mesmo e enxergar as emoções que se expressam em produções simbólicas, desejos, medos e ambições, por isso digna de atenção e cuidado. O conceito de alma aparece muitas vezes na bíblia e em nenhum caso sustenta alguma dicotomia em relação ao corpo, pelo contrário, se integra ao corpo na recepção do Espírito Santo que penetra profundamente nas juntas e medulas a fim de discernir os pensamentos e intenções do coração (Hb 4,12).

Por sua natureza, a pessoa enfrenta dificuldades, limitações físicas e psíquicas, mas é pelo cuidado que ela pode significar sua existência: o amor é 
evocado. O cuidado, no sentido meramente moral, pode ser exercido por exigência da própria cultura e das relações sociais e jurídicas, justificadas pelo Estado de direito. Porém, sob a práxis da fé e da consciência do Espírito, o cuidado torna-se solidário e responsável, busca para o outro o que pretende para si mesmo (Mt 7,12). O cuidado, nesta perspectiva, é pura gratuidade, pois valoriza o outro, ouve sua dor e age em função de sua regeneração. Uma ação que rompe os limites culturais e possibilita atitudes de solidariedade (MEDEIROS, 2010).

\section{Conclusão}

Procurou-se não perder o objetivo desta reflexão: apresentar a trajetória do Espirito Santo e o cuidado na Igreja, na perspectiva da História da Salvação. O Espírito é fundante na história da criação e da salvação. É a Ruah que acolhe, escolhe, unge e inspira pessoas a enxergarem além da materialidade das coisas. Por sua ação, se renunciam ao individualismo e ao egoísmo, posturas desagradáveis na construção de uma sociedade mais justa e igualitária, ainda nesta terra.

No Primeiro Testamento, como se viu, o Espírito se apresenta através de metáforas de responsabilidade e cuidado. São metáforas ligadas à criação, à profecia e à lei. O Espírito, em sua dimensão feminina, acolhe e hospeda em seu interior toda criatura e a vivifica. Esta atitude se manifesta num contexto de desintegração no plano de Deus. Os profetas são eleitos e ungidos para reintegrar a criação e reestabelecer a relação com Deus. No que tange à lei as metáforas da unção e inspiração são fundamentais para reestabelecer o que foi dividido pelo pecado: a aliança entre Deus e os seres humanos. Tais metáforas expressam essencialmente a alteridade do Espírito.

No Segundo Testamento o Espirito Santo é testemunhado nos evangelhos e nas cartas apostólicas e está intimamente ligado à pessoa de Jesus Cristo. Se João Batista pregava o arrependimento e batizava com água, Jesus batiza com espirito Santo, fazendo acontecer na vida de seus seguidores o que presenciou na sinagoga 
de Nazaré ao ler a passagem de Isaías 61,1-2: “O Espirito do Senhor está sobre mim...”. Em Jesus as metáforas que tornavam visíveis o Espírito se encarnam e revelam o plano de Deus para a criação e à humanidade.

O Espírito Santo falou pelos profetas, atuou na pessoa de Jesus para que cumprisse a missão do cuidado, principalmente no que se refere aos mais necessitados, e continua a animar a igreja hoje. A teologia do Espirito Santo é atual, tal como foi ressaltada em Atos dos Apóstolos (13,2; 16,6), afirma ainda hoje que o Espírito Santo continua a obra do Pai no Filho: acolhe, escolhe, unge e inspira pessoas para a proclamação e implantação do Reino de Deus na terra.

Espírito, cuidado e responsabilidade são conceitos que se colocam à reflexão daquele que se interessa pela práxis cristã e, por desejo próprio, quer se disponibilizar a uma pastoral solidária junto àqueles que sofrem. Em sua prática, é fundamental que o cuidador adote um método adequado às várias situações; que ajude as pessoas em seu processo de libertação do sofrimento; que analise os discursos a partir da Palavra de Deus, inspirada pelo Espírito Santo, e aponte saídas práticas a fim de contribuir na formação de pessoas comprometidas com a vida.

\section{REFERÊNCIAS}

AGOStinHO, Santo. A Graça I, (Patrística). São Paulo: Paulus, 1998.

BASÍLIO DE CESARÉIA. Tratado Sobre o Espírito Santo, série V, in Patrística. São Paulo: Paulus, 1998.

BOLGIANI, F. Espírito Santo. In: BERARDINO, Angelo Di. (org.). Dicionário Patrístico e de Antiguidades Cristãs. Petrópolis: Vozes, 2002.

ClEMENTE ROMANO. Aos Coríntios. In: Padres Apostólicos (Patrística). São Paulo: Paulus, 1985.

CODINA, Victor. Não extingais o Espírito. São Paulo: Paulinas, 2010.

CONGAR, Yves. Ele é o Senhor e dá a vida, I. São Paulo: Paulinas, 2005. 
CONGAR, Yves. Ele é o Senhor e dá a vida, II. São Paulo: Paulinas, 2005.

HABERMAS, Jürgen. Fé e Saber. São Paulo: UNESP, 2013.

LÉVINAS, Emmanuel. Entre Nós: Ensaio sobre a Alteridade. Petrópolis: Vozes, 2005.

LÉVINAS, Emmanuel. Quatro Leituras Talmúdicas. São Paulo: Ed. Perspectiva, 2003.

MARTINS, Alexandre A. A Pastoral da Saúde e sua importância no mundo da saúde: da presença solidária ao transcender a dor e o sofrimento. Revista O Mundo da Saúde, São Paulo, v. 34, n.4, 2010.

MEDEIROS, Veroni T. Alteridade e Ética Cristã: A Novidade Para Um Ser Humano Solidário na Teologia de Bruno Forte. Dissertação de Pós-Graduação, PUC-RS. Porto Alegre, 2010.

MIES, François. Emmanuel Lévinas e a Bíblia. In: MIESS, François (org.). Bíblia e Filosofia. São Paulo: Loyola, 2012, pp. 113-156.

TILLICH, Paul. Teologia Sistemática. $6^{\mathrm{a}}$ edição revista. São Leopoldo: Editora Sinodal, 2005. 